qualified in 1866 with a thesis on the anatomical lesions in general paralysis. The following year he was appointed physician to the Asile Sainte-Anne, to which he was attached for forty-five years. His most important work was concerned with the psy. choses produced by alcoholism, in the modern investigation of which he was a pioneer, absinthe, in the prohibition of which in France he was mainly instrumental, and morphia; epilepsy, and sexual anomalies and aberrations. As director of SainteAnne, where he founded the Société clinique de médecine mentale, he was an enthusiastic advocate of the no restraint system and especially of the suppression of the straight-jacket. His clinical lectures, which attracted numerous French and foreign physicians to Sainte-Anne, were for thirty years published in Le Progrès Médical, of which the issue for June 8 commemorates the centenary. In 1893 he was elected a member of the French Academy of Medicine, of which he became president in 1915. In his will he left the sum of 25,000 francs to the Academy for the foundation of a prize in psychiatry which bears his name. His death took place on September 27, 1916, when he had reached the age of eighty-one years, his faculties remaining intact until the end.

\section{Basutoland in Transition}

Fundamental changes in the life and economy of the natives of Basutoland are foreshadowed by the report (Cmd. 4907. H.M. Stationery Office) of the Commission, of which Sir Alan Pim is chairman, appointed by the Secretary of the Dominions to inquire into the financial and economic position of the country. The recommendations are drastic and affect almost every aspect of native life. The gravity of the financial situation, which dictated the appointment of the Committee in the first instance, shows no sign of alleviation, and even in the improb. able contingency that the proposals are entirely set aside, the force of circumstances alone, it would seem, will bring about disastrous changes which will lead to the breakdown of native culture and the system of administration. The spirit of independence and pride of race characteristic of the Basuto people should be preserved at all costs as the essential condition of their future progress. Their spirit is explicitly recognised in the Report as a dominant factor in the problem of reform ; but it is pointed out that, unless rightly directed, it may prove an obstacle in the way of advance towards the goal the Commission has in view - the creation of a real system of 'indirect rule'. In the multiplicity of topics discussed and of ameliorative measures suggested, this is the major issue. While the financial situation of the Protectorate has undoubtedly complicated its political future, the internal situation and the formulation of a settled administrative policy which will afford opportunity for the development and utilisation of the admittedly favourable traits in native character and culture must obviously be a prior consideration to that of the eventual transfer of responsibility to the Union of South Africa.

\section{R.A.F. Big Flying Boat}

THe performance figures of the Saraband built by Short Brothers of Rochester for the R.A.F., just divulged for the first time although the machine was built in 1932, show that it is by far the largest flying boat in the R.A.F. equipment, and is more powerful than even the German D.O.X. Its engines total 5,500 horse-power, maximum speed 150 miles an hour, climb $750 \mathrm{ft}$. a minute, with an air range of 1,450 miles, with full load. In this respect it is worth remembering that many countries make a practice of reporting performance trials with specially light. ened loads. The machine has a wing span of $120 \mathrm{ft}$. and is $90 \mathrm{ft}$. long. It carries a military load of 5,960 lb., which includes an automatic pilot, the usual machine guns, and a $1 \frac{1}{2}$ in. automatic quick firer. The hull is a self-contained unit, containing sleeping accommodation for the crew, a workshop, a ward room, a drying compartment, an anchor winch, and gear for changing engines afloat. It is built entirely of steel and duralumin, and the hull design incorporates many novel structural features. A civil flying boat of the same size was under construction at the same time, but was stopped for reasons of economy.

\section{Presentation of Prof. Piccard's Gondola to the Science Museum}

ON June 12, the gondola of the balloon in which Prof. A. Piccard and M. Max Cosyns ascended into the stratosphere on August 18, 1932, was presented to the Science Museum, South Kensington, by M. Jean Willems, director of the Fonds National de la Recherche Scientifique, Brussels. His Excellency the Belgian Ambassador presided, and both Prof. Piccard and M. Cosyns were present. The gondola consists of an air-tight sphere (about 2 metres in diameter) of aluminium alloy, fitted with two manholes and several portholes, and equipped with various scientific instruments; it was attached to the hydrogen-filled balloon with which Prof. Piccard made his previous ascent on May 27, 1931. The second ascent, in 1932, was made from Dübendorf Aerodrome, near Zurich, and after a twelve-hour flight, the balloon landed safely in a field at Cavallaro di Monzambano, about ten miles south of Lake Garda. The maximum height reached during the voyage (determined trigonometrically) was 16,940 metres (10 $\frac{1}{2}$ miles). The main objective of the flight was the investigation of cosmic radiations. Observations were made to ascertain the variation of intensity of these rays with height, and the distribution of the radiation in different directions was studied by means of a tubular Geiger counter.

\section{Early Design for an Aeroplane}

The Science Museum, South Kensington, has just acquired through the generosity of Mr. P. A. Smith of Scarborough a small disc of silver about an inch in diameter bearing an engraved design for a flying machine which is remarkable in conception. The disc bears the initials 'G.C.' with the letter ' $R$ ' beneath and it is dated 1799 . The reverse contains a diagram of forces relative to the design illustrated. 